Relations industrielles

Industrial Relations

\title{
Le syndicalisme obligatoire devant la morale. Gérard Dion. Collection « Etudes Sociales ", La Pensée catholique, Bruxelles, Office général du livre, Paris, 1957, 64 pp.
}

Volume 13, numéro 2, avril 1958

URI : https://id.erudit.org/iderudit/1022449ar

DOI : https://doi.org/10.7202/1022449ar

Aller au sommaire du numéro

Éditeur(s)

Département des relations industrielles de l'Université Laval

ISSN

0034-379X (imprimé)

1703-8138 (numérique)

Découvrir la revue

Citer ce compte rendu

(1958). Compte rendu de [Le syndicalisme obligatoire devant la morale. Gérard Dion. Collection « Etudes Sociales », La Pensée catholique, Bruxelles, Office général du livre, Paris, 1957, 64 pp.] Relations industrielles / Industrial Relations, 13(2), 235-235. https://doi.org/10.7202/1022449ar

Tous droits réservés (C Département des relations industrielles de l’Université Laval, 1958
Ce document est protégé par la loi sur le droit d'auteur. L'utilisation des services d'Érudit (y compris la reproduction) est assujettie à sa politique d'utilisation que vous pouvez consulter en ligne.

https://apropos.erudit.org/fr/usagers/politique-dutilisation/ 


\section{RECENSIONS - BOOK REVIEWS}

Le syndicalisme obligatoire devant la morale. Gérard Dion. Collection « Etudes Sociales », La Pensée catholique, Bruxelles, Office général du livre, Paris, 1957, 64 pp.

Lors du deuxième Congrès des relations industrielles de Laval, en 1947, l'abbé Gérard Dion avait présenté une étude remarquable sur la sécurité syndicale et la morale. Le tiré-à-part qui en avait été fait est depuis longtemps épuisé. Comme ce problème garde toujours son actualité et que les principes invoqués par l'auteur restent toujours vrais, la direction de «La Pensée catholique » de Bruxelles a décidé d'en préparer une nouvelle édition. On a cependant omis la première partie du travail qui traitait de la notion de la sécurité syndicale et des définitions des différentes clauses dans les conventions collectives, car une autre brochure de la même collection ( $L a$ sécurité syndicale par Jean Neuville) y avait pourvu.

La thèse de l'abbé Dion est la suivante:

«Dans le conflit apparent qui semble exister entre les clauses de sécurité syndicale et le droit au travail pour les ouvriers et le droit de gestion pour l'employeur, celles-ci ne viennent détruire aucun droit, mais elles ne font que les conditionner, et d'une façon légitime en vue d'un intérêt supérieur.

«Pour obtenir ces clauses, le syndicat peut user de pressions économiques, mais il doit remplir certaines conditions dont les principales sont d'être réellement l'organe qui représente la communauté des travailleurs dans un établissement et en poursuivre vraiment et exclusivement le bien commun sans violer la liberté de conscience et en tenant compte des principes de justice, de charité. »

L'étude lucide et solide de l'abbé Dion a clarifié bien des concepts et dissipé bien des malentendus. Elle a surtout contribué à ramener les discussions autour de la sécurité syndicale sur leur véritable plan, c'est-à-dire celui de l'opportunité dans des circonstances parti- culières. Nous ne doutons pas que cette réédition continuera à rendre de grands services.

A Social Profile of Detroit: 1956. A Report of the Detroit Area Study of the University of Michigan. Detroit Area Study, Department of Sociology and the Survey Research Center of the Institute for Social Research, 1957. 83 pp. $\$ 1.50$.

L'Université du Michigan a mis sur pied, en 1951, un organisme permanent de recherche consacré à l'investigation sociologique de la zone métropolitaine de Détroit. La présente brochure constitue le cinquième rapport publié par cet organisme. Destiné à un large public, ce document ne fournit que les résultats préliminaires d'une enquête menée au début de 1956. L'enquête, cette fois, a porté plus particulièrement sur la mobilité résidentielle, sur le revenu des familles, sur les attitudes relatives au travail féminin hors du foyer et sur le degré d'homogénéité des valeurs (religieuses, politiques, etc.) auxquelles adhèrent les membres de la collectivité.

Attachons-nous ici à certaines des observations rapportées à propos du revenu des familles et du travail féminin.

Détroit est depuis longtemps un centre où les revenus sont relativement élevés. En 1955, 50\% des familles jouissent d'un revenu brut supérieur à $\$ 5,700$; le revenu familial médian a ainsi augmenté de $7 \%$ par rapport à 1954 et de $24 \%$ par rapport à 1951. Il est à noter, toutefois, que cet accroissement ne s'accompagne pas d'un nivellement des revenus: entre les revenus des familles d'ouvriers non qualifiés et ceux des familles de la classe la plus favorisée, l'écart reste à peu près constant. A noter aussi une étroite corrélation entre le niveau d'instruction et le rythme de croissance du revenu.

En 1900, aux Etats-Unis, les femmes ne comptaient que pour $18 \%$ de la population active; de 5 millions, leur nom- 